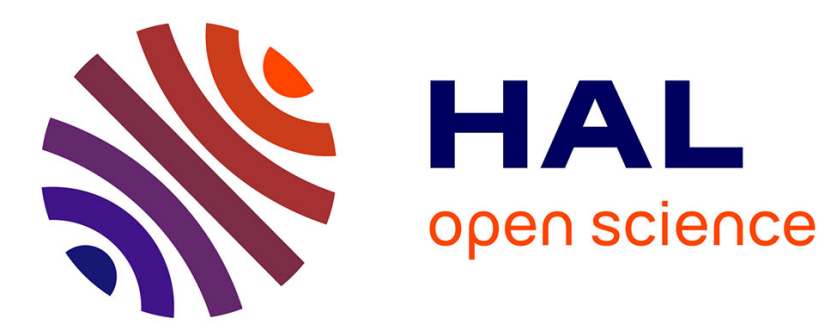

\title{
Devil in The Digital: Ambivalent Results in an Object-Based Teaching Course
}

Mark Turin

\section{To cite this version:}

Mark Turin. Devil in The Digital: Ambivalent Results in an Object-Based Teaching Course. Museum Anthropology, 2015, 38 (2), pp.123-132. 10.1111/muan.12088 . halshs-03083451

\section{HAL Id: halshs-03083451 https://shs.hal.science/halshs-03083451}

Submitted on 27 Jan 2021

HAL is a multi-disciplinary open access archive for the deposit and dissemination of scientific research documents, whether they are published or not. The documents may come from teaching and research institutions in France or abroad, or from public or private research centers.
L'archive ouverte pluridisciplinaire HAL, est destinée au dépôt et à la diffusion de documents scientifiques de niveau recherche, publiés ou non, émanant des établissements d'enseignement et de recherche français ou étrangers, des laboratoires publics ou privés. 


\section{DEVIL IN THE DIGITAL: Ambivalent Results in an Object-Based Teaching Course}

\section{Mark Turin}

UNIVERSITY OF BRITISH COLUMBIA

\section{ABSTRACT}

In 2013, I piloted a course in which students used Webbased tools to explore underdocumented collections of Himalayan materials at Yale University. Through classbased research and contextualization, I set students the goal of augmenting existing metadata and designing media-rich, virtual tours of the collections that could be incorporated into the sparse catalogue holdings held within the library system. The process was experimental and had mixed results, as this article documents. The class provided an opportunity for undergraduate students from any discipline to work with objects and primary materials, requiring them to evaluate different sources of information, value, and legitimacy. Learning outcomes were nontraditional and intentionally underscripted. The collaborative and hands-on approaches toward digitization that de-emphasized the authority of the instructor were unsettling to some students. [digital humanities, mobile classroom, critical pedagogy, material culture, Himalaya]

\section{From Collections to Connections}

What can students unfamiliar with the histories and provenance of a set of apparently unrelated objects held by a university contribute to the knowledge and understanding of these objects? How can objectbased teaching and the application of digital tools in the classroom foster a learning environment that is socially relevant and culturally engaged with an afterlife beyond the semester? Finally, what structures and protocols can be set in place to help make such courses sustainable over time?

These were some of the questions that motivated me to pilot a new course in the fall of 2013 at Yale University. During my three years in New Haven, I had been surprised by two features of the institutional landscape in which I was working. First, while students were on the whole extremely motivated and driven, they were quite traditional in their expectations of learning outcomes and classroom hierarchy.
Analytical and discursive writing assignments were still the norm and were generated for an instructor to review and evaluate. It seemed a shame that such effort was destined solely for my inbox, and I wanted to experiment with creating a more connective, longerlasting, and less text-driven classroom. I had been inspired by recent work that focused on emergent pedagogies in the digital humanities (see Hirsch 2012) and the opportunities provided by digitally mediated and more collaborative learning environments.

Second, Yale University was home to considerable collections from and about the Himalayas, a region in which I had worked for over 20 years. While most of these collections had been donated by collectors and alumni, others had been purchased with acquisition budgets made possible by a large endowment. From art to archives, publications to personal correspondence, and manuscripts to religious artifacts, Yale's Himalayan holdings were located across the university landscape in libraries, galleries, archives, and museums. As intriguing as the diversity and richness of the collections was the discovery that, according to available records, no faculty member or curator at Yale had ever brought these disparate holdings into conversation through a class or an exhibit. As Kathleen Adams notes in her introduction to this issue, the presence (or absence) of ethnographic collections within one's own university can exert a powerful influence over one's intervention and pedagogy. In my case, these underutilized materials and objects provided an opportunity for contextualization and reassembly.

In the spring of 2013, Andrew Quintman (a faculty member in the Department of Religious Studies), Sarah Calhoun (the librarian for South Asian Studies), and I curated a small, temporary, and public exhibit to highlight Yale's involvement with the Himalayan region by showcasing some of the collections (Figure 1). This modest exhibit helped me to envision a class that could offer a deeper exploration of these collections and their contexts.

The exhibit also reminded me of the extent to which students still perceived university archives, museums, and libraries to be dusty, quiet, and mostly inanimate places where objects are preserved for posterity. Coverage of the exhibit and feedback from visitors indicated that 19th-century characterizations and negative misrepresentations about the work that 


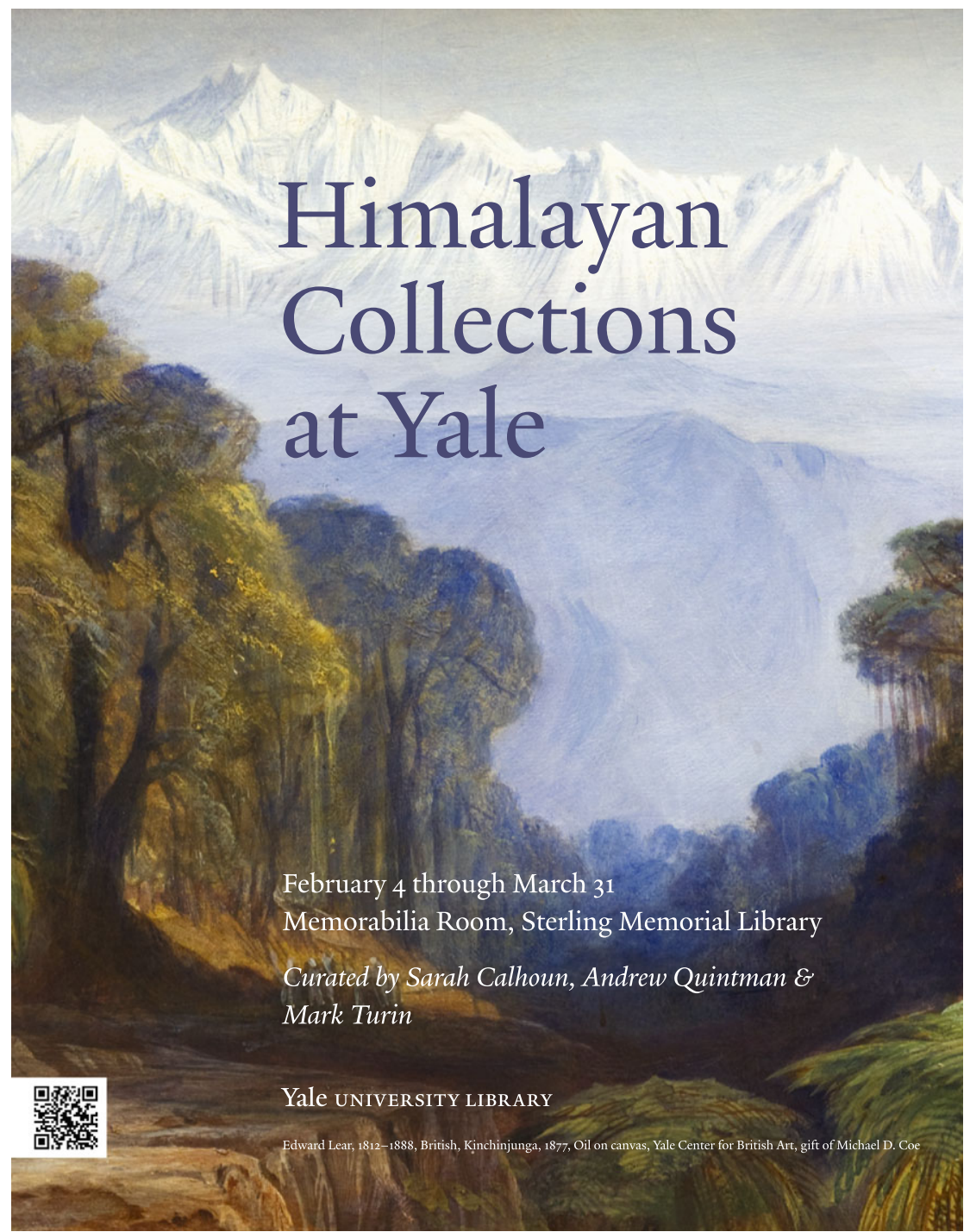

Figure 1. Himalayan Collections at Yale exhibit poster.

went into managing collections were quite entrenched. A February 6, 2013, article in the Yale Daily News entitled "Himalayan Exhibit Unites Regional Artifacts" opened with the revealing line: "There's a revolution brewing beneath the Stacks" (Hallam 2013:4).

Still, that a student newspaper had understood the exhibit to have been "created in the hopes of bridging the gap between departments studying the Himalayas separately" (Hallam 2013:4) was an indication that our intervention might have worked. Could we point to an emerging realization (and appreciation) that libraries, museums, and archives were as much sites of innovation and creation as they were places of protection and preservation? Perhaps a course that straddled disciplines and worked through and across collections would provide an opportunity to explore sensorial engagements with material holdings and promote object-based teaching around Yale's Himalayan collections.

\section{Bits and Bytes: The Medium or the Message?}

While it has "long been a central canon of museum philosophy that fossilized collections die" (Mayhew 2006:87), there has not yet been an equal recognition that digital collections are equally vulnerable - perhaps even more so-albeit in different ways. Through a digitally mediated class, I hoped that students would come to appreciate the impact of Moore's law on the exponential rate of technological change in computing, a realization that can provide a powerful, if brutal, lesson in impermanence and non-attachment to external form. ${ }^{1}$ The rate of innovation and the pace of obsolescence were moving ever faster, and the curious 
challenge of online collections was that they appeared to exist everywhere and nowhere, at once infinitely replicable and thus seemingly safe, yet dangerously fragile if not backed up or regularly migrated.

Academic practice is changing and so too are the expectations of those with whom we work - students, colleagues, and research partners. In terms of ethnographic materials, it struck me that the analog (at least as retained and curated in museums and in private collections) was at no risk of disappearing, but rather it ran the risk of being disconnected from experiences that were increasingly - and sometimes exclusivelymediated through the digital. If something was not discoverable through an online search or a digital catalogue, it could appear to not exist at all. Unpacking and exploring the processes by which some objects are selected for digital display and dissemination while others are not would be fertile ground for a class.

While we all know that digital tools are neither objective nor value neutral, the digital turn can facilitate the "formation of relationships of trust and cooperation, rather than those of exclusion or superiority" (Scott 2012:2). The digital can provide us with a platform to reassemble the analog; it allows us to explore new forms of collaboration and teaching that might be more creative, more subversive, and more equitable. In addition, I hoped that an object-based class might offer a framework to integrate different knowledge systems and challenge existing hierarchies of value, and thereby transform my experience of teaching and the students' experiences of learning in exciting and generative ways.

Could students explore and come to terms with the uneven and sometimes surprising valence of historical collections and objects through a class? "The essential ambiguity of digital culture" relates to its ability to be open at the same time it is closed, and this emerges "in matters ranging from politics and privacy to the authenticity of ambivalence" (Horst and Miller 2012:4). While we might like to think of each cultural object or artifact as having its own life history - a unique trajectory through time and space - the voices of individual documents have a tendency to be flattened by the anonymity of large archives or constantly reshaped by changing sociopolitical contexts. In some cases, the sheer volume of documents, whether analog or digital, can reduce a unique image, audio file, or artifact to one in a series, a point of unaffiliated data. Similarly, the individuals involved in a document's life are often left by the wayside when a document becomes assimilated into an archive: subject, collector/artist, and interpreter can be collapsed into notes in the margin.

\section{From Digital humanities Research to the Digital Classroom}

Since 2000, I had been involved in various initiatives and collaborations that are now referred to as digital humanities projects. Principal among these was the Digital Himalaya Project, a collection, storage, and dissemination portal for scholarly content and research findings about the Himalayan region (see Turin 2012). ${ }^{2}$ While the project began as a strategy for collecting and protecting mostly colonial-era ethnographic collections on the Himalayas - for posterity and for access by source communities - it had quickly developed into a collaborative digital publishing environment supported by an active and global community of contributors.

Prior to my experience of co-curating the Yale exhibit, I had never considered how my digital explorations and Web-based projects might work in a classroom setting. It was only when challenged by Dean Irvine, visiting professor at Yale and director of the Editing Modernism in Canada Project (EMiC), about why I had effectively located my research questions in a silo separated from my pedagogy did I begin to explore how the two might interact. In my limited experience, university recognition and reward structures did not generally incentivize faculty to explore more collaborative, cloud-based, and democratic instructional formats. As a case in point, I had recently learned of an environmental scan of digital humanities centers in North America that concluded, quite unsurprisingly, that the leading units and institutes were to be found in state schools rather than at Ivy League schools and other private institutions.

I applied for an internal university fellowship to develop a hands-on and collaborative class that would explore the links among Yale's collections from and about the Himalayan region by tasking students with developing basic catalogue entries and producing virtual and media-rich tours. While an element of restricted crowd sourcing was built into the proposal, the pedagogical focus was firmly on student-led 
digitization and online projects that would add some context to these little-documented collections. If successful, these interventions and explorations would then be incorporated into the existing catalogue holdings and made visible through library, museum, and archive search tools. When producing their online exhibits, students would have to bear in mind that what they produced would be visible to all and endure beyond the class.

Entitled "Himalayan Collections," the class would move between sites across campus, from analyzing photographs at the art gallery, to learning about Tibetan Buddhist scrolls at the Beinecke Rare Book and Manuscript Library, to unpacking an archive of missionary documents at the Divinity School Library, and investigating personal and political papers deposited by a former ambassador held in manuscripts and archives at the Sterling Memorial Library. The course was envisioned to be inherently collaborative, with students learning from each other and working together in noncompetitive ways, and it was unusual in terms of its array of teachers-an untenured adjunct professor, an instructional technologist, a graduate teaching fellow, and two staff from the library system. Our funding was used to hire a graduate teaching assistant for the semester, cover information technology (IT) and design costs associated with the adoption of our class platform, and pay for travel and accommodation for a number of guest lecturers from across the United States who could offer insights into specific collections that the class was exploring.

\section{The Pedagogy of Collaboration: Challenging Established MOdels and Expectations}

Developing and publicizing a new course that challenged established disciplinary models of scholarship and positioned students as co-creators of socially relevant knowledge was harder than I had imagined. The first task was working with different departments to secure cross listings, meaning that the course could count toward a major in their discipline. By the time the course went live, four instructional units had signed off on the syllabus and seen fit to assign their own course code to the pilot class: Anthropology, History of Art, South Asian Studies, and East Asian Studies.

The next challenge was to build the instructional team. In total, seven different individuals were involved with the design, implementation, oversight, and evaluation of the class, four of whom were central to the realization of the course. As the only faculty member on the team, I was listed as the instructor of record. I was closely supported by Calhoun, co-curator of the earlier exhibit and librarian for South Asian Studies at Yale. Calhoun attended most class meetings, assisted students in understanding archival practices and library cataloguing processes, and guided many of the students in their explorations of additional content. Luke Wagner, a Ph.D. student in sociology at Yale who had lived in the Himalayan region for some time prior to starting graduate school, agreed to be the teaching fellow. Wagner was the first point of contact for student inquiries - of which there were many-and the main logistician behind the mobile classroom that we had envisaged. He also managed the scheduling of our access to the collections and the logistics of our visiting speakers, and he participated in each class.

Trip Kirkpatrick, senior instructional technologist at Yale, was the final member of our core team. Kirkpatrick took on the responsibility of implementing and maintaining our chosen technical infrastructure, Omeka, and for training and supporting students as they grappled with the platform and other tools. Kirkpatrick assisted students in the classroom and during regular office hours, searched long and hard for useful plugins, and served as the first port of call for all technical difficulties. In addition to the core team of four, we benefitted from the graphic design skills of Daniel Ho for our Omeka collections website and Chika Ota for our course poster (see Figure 2), and also from Peter Leonard, the newly hired librarian for Digital Humanities Research at Yale, who attended a number of our classes at the start and end of the semester to illustrate what could be achieved through creative and visual approaches to big data that leveraged open access collections.

Assessing and assigning different responsibilities, and ensuring that line managers at central IT and the university library system were on board with their staff members spending so much time in the classroom and in meetings, was one of the most timeconsuming and yet fulfilling aspects of teaching the class and is a feature of many digital humanities collaborations. As an anthropology student in the early 1990s, I had been inspired by Alison King's 


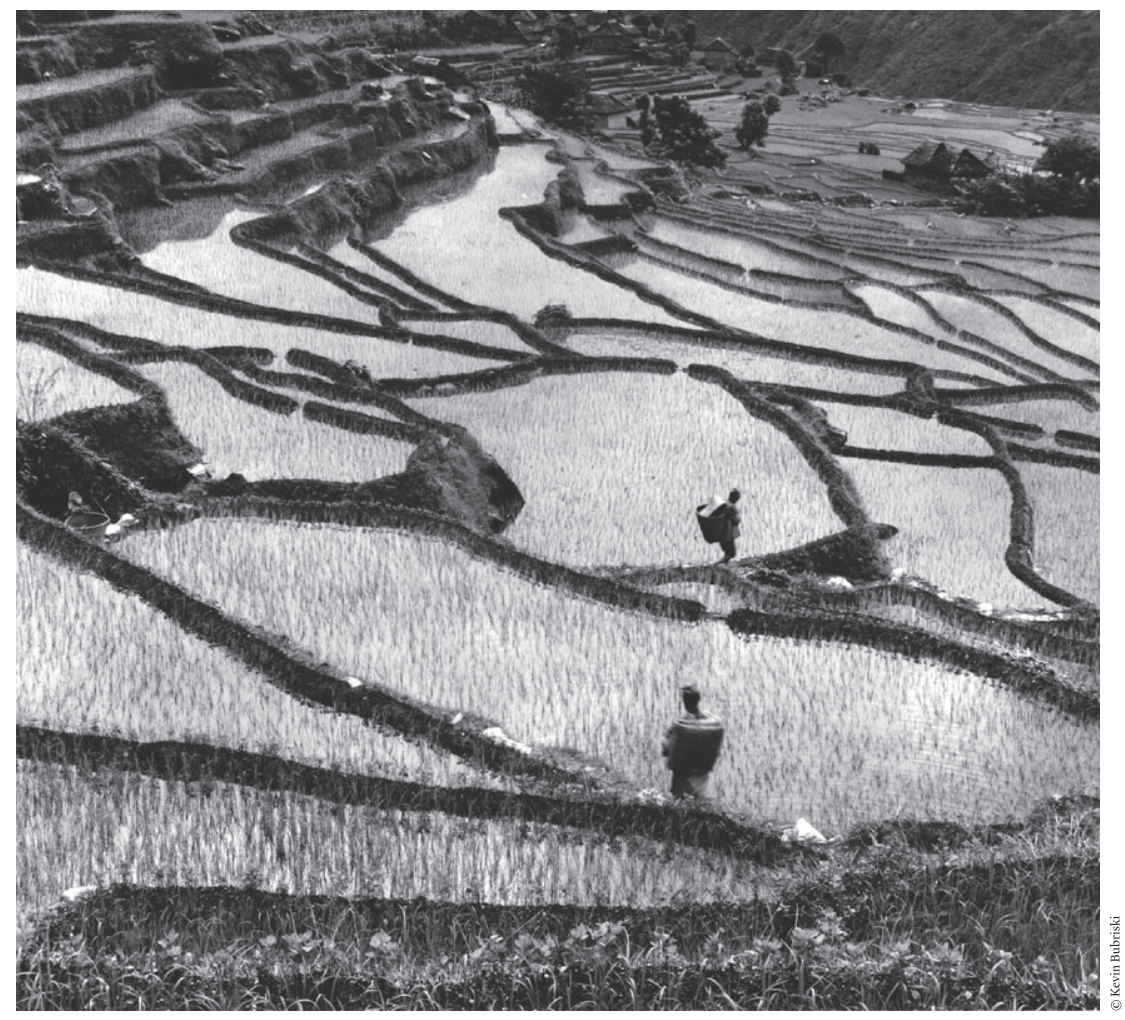

\title{
Himalayan Collections at Yale
}

\author{
An experimental course to explore and uncover Yale's unique collections of Himalayan materials \\ ANTH 317/EAST 363/HSAR 479/SAST 363 - FALL 2013 - TUESDAY 3:30-5:20 PM \\ bit.ly/HimalayanCollections \\ 凶ark.turin@yale.edu $v$ @markturin
}

Figure 2. "Himalayan Collections at Yale" course poster.

(1993) call to arms "From Sage on the Stage to Guide on the Side," but it was only now, as a faculty member, that I felt I had an opportunity to try something along these lines. Echoing the work of Paulo Freire, King makes the compelling argument that most college classrooms are based on a transmittal model of learning in which the "professor lectures and the students take notes” (1993:30). This model effectively assumes that the "student's brain is like an empty container into which the professor pours knowledge" and that "students are passive learners rather than active ones" (King 1993:30).

I hoped that an object-based and collaborative teaching model informed by a more sensorial approach to materiality might help, as King concluded her short but influential article, to "move away from the reproduction of knowledge toward the production of knowledge" (1993:35) and better prepare my students for the increasingly interdisciplinary and modular nature of contemporary life. What surprised me and other members of the instructional collective was how resistant some of the students were to the dismantling of the Sage on the Stage model. The established hierarchy of expertise-with a professor at the top, a graduate teaching assistant under their direction, and IT and library staff in the wings to serve the instructional and research needs of the students and faculty alike-was more entrenched than we had expected. As the student evaluations that I share below illustrate, there were real concerns among the students who enrolled in the class about an erosion of expertise and unclear notions of value, skill, and knowledge. I was surprised by this pushbackparticularly because I had been so stimulated by my 
partnerships with librarians, archivists, and technologists through my work in the Digital Himalaya Project - and had not imagined the landscape of digital pedagogy to be so conservative and entrenched, certainly in comparison to the more open and inclusive field of digital humanities research.

\section{The Mobile Classroom: Bringing the StudentS TO THE OBJEcts}

We had designed the class in an experimental and modular way, moving between five locations during the 13-week semester. It was logistically far easier to bring the class to the collections than the collections to our class. We were eager to expose students to the rare pleasure of working with, handling, examining, and exploring primary materials during their undergraduate careers (Figure 3). We wanted to encourage and build the critical faculties that would help students evaluate different sources of information, weigh their value and legitimacy, and be mindful of the enduring residue of their coursework in the archive. In their introduction to Sensible Objects, Elizabeth

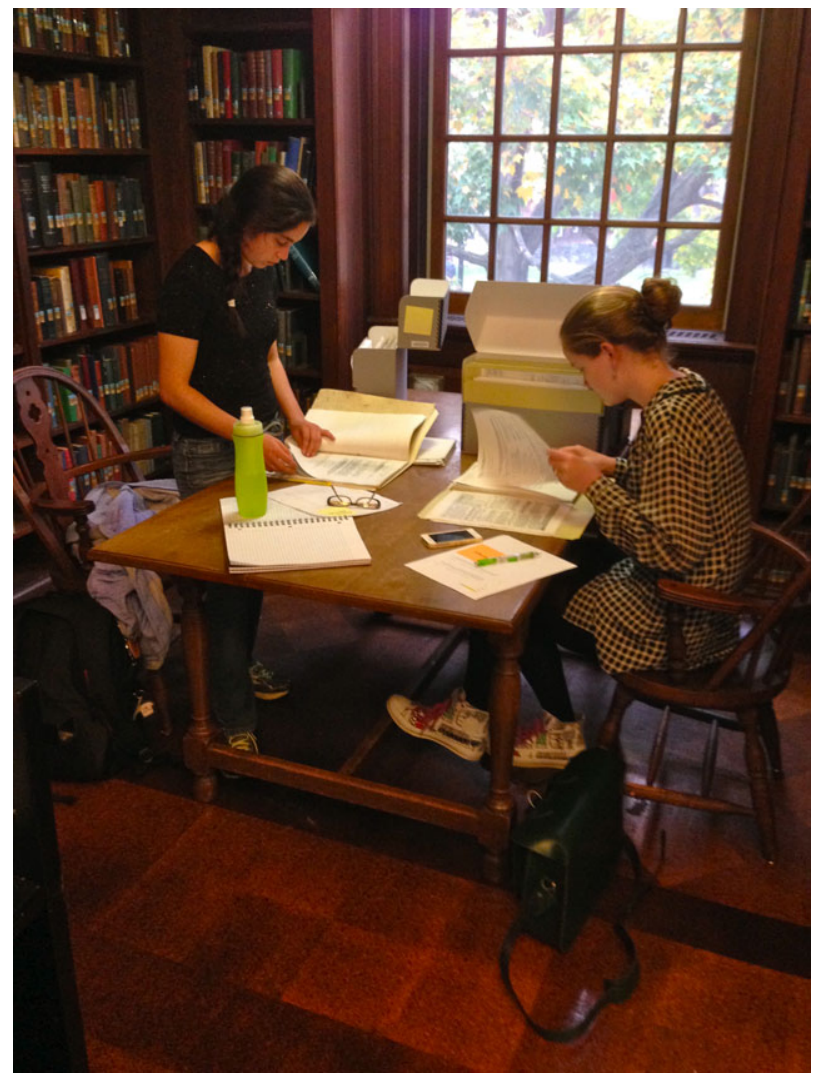

Figure 3. Students in the course working with the Himalayan Mission Archive Collection at the Yale Divinity School, 2013.
Edwards et al. (2006) ask the question: "What do objects want?" My own, albeit internalized, answer was that these collections held in different locations within the same institution might be enriched by being in conversation with one another, which would allow for an exploration of the interrelationships and narratives of their acquisition and decontextualization, as well as the overarching colonial framework that had shaped the terms of their original accessioning and curation. Edwards et al. explore three interventions in the context of reinvigorated sensorial regimes, of which we aimed to engage with two:

objects [that] have been removed from museums and recontextualized outside them, and forgotten technologies of manufacture [that] have been recovered through embodied engagements with historical objects which may have major impacts on material culture outside the museums walls. [2006:21]

We selected four major collections on and about the Himalayan region as the primary material for the class and hoped that by engaging with these historically diverse materials as primary sources, students would learn about the history, materiality, and context of how these collections came to the university and also understand the specificities of each medium and genre (i.e., art, photography, personal archive, missionary documents). Alongside this intellectual and analytical work, an important aspect of the class involved students working together to digitize and collaboratively catalogue part of a collection. In lieu of a textual final paper, all students were expected to produce a media-rich, online exhibit for one subset of a collection (or to combine aspects of different collections). Because these exhibits would be public documents and endure beyond the class, we encouraged students to imagine them as helping to enrich the understanding and appreciation of these collections and objects for others in the future. This sense of scholarly service did not sit well with all participants, as will be clear from the student evaluations shown below.

The class started and ended in Yale's Technology Enabled Active Learning (TEAL) classroom. The TEAL classroom, decked out with 14 round tables, 14 flat screen displays, 8 whiteboards, 5 projection screens, and numerous microphones and video 
cameras, was overkill for our small class with its modest technical requirements. While certainly impressive, I came away thinking that the overwhelming technological sophistication of the room may have resulted in a more mediated and technologized interaction with the objects than we had intended. In retrospect, I also fear that by bookending our class explorations in such a digitally saturated space, we had given the mistaken impression that the goals of the course were driven by the abilities of the technology rather than the richness of the content. As is well documented, many digital humanities research initiatives start out in the corner of an office, tied together with insufficient resources and home-grown technologies. The TEAL classroom rather appeared to put the tools front and center.

In the first few weeks of the course, we focused on establishing basic visual literacy. As a student, I had been impressed by James Monaco's (1981) How to Read a Film and John Berger's (1973) Ways of Seeing, and I wanted to challenge my students to move beyond the comfort zone of visual (and multimedia) consumption to a more critical and reflexive position. As Christina Kreps notes in her contribution in this volume, few students know how to read the material and visual worlds around them. Having established a theoretical baseline, we visited the four carefully selected collections across campus, in each case with the assistance of a local guide. In the art gallery, we met the photographer, Kevin Bubriski, whose photos we were exploring, which allowed students to first ask questions of the photos and then of the photographer himself; in the Beinecke Rare Book and Manuscript Library we welcomed a Tibetan monk and highly regarded artist, Lama Tsondru Sangpola, to guide us in our exploration of Buddhist thangkas, religious scroll paintings from the Himalayas. We also invited Himalayan art historian Ariana Maki, lecturer and curator at the University of Colorado-Boulder, to help us understand the social and cultural context of thangka production. When exploring the political and missionary archives, we benefitted from the insights of University of Colorado professor Carole McGranahan, an anthropologist and historian of Tibet with a strong interest in digital scholarship and archival research.
The course website offered a working space for mini-projects during the class and also a platform to host all the final student projects that were designed for the public. ${ }^{3}$ The entire class was experimental and had mixed results, and the remainder of this article reflects on these successes and challenges through the lens of the student experience.

\section{From Proof of Concept to Sustainable Pedagogy?}

This course was not sustainable in the format that we had piloted it. As an upper-level seminar with only 13 students but supported by 4 co-instructors and an external grant to cover additional costs and a range of visiting speakers, this level of commitment, engagement, and mentoring could not easily be repeated. In addition, the class was somewhat destabilized by the fact that we were addressing serious issues of representation, authority, and materiality without the students having a common background in a shared discipline. In effect, we were exploring the cultural biographies of objects through the prism of the Himalayan region, but because both the theoretical work and the regional context were new to many of the students, it was a stretch for many, instructors included. We encouraged students to examine their own role in shaping the cultural biographies of the objects and materials that they were handling and grapple with the central realization that "as people and objects gather time, movement and change, they are constantly transformed, and these transformations of person and object are tied up with each other" (Gosden and Marshall 1999:169).

In her introduction to this issue, Adams reflects on the "pervasive, culturally constructed divide between the mundane material world of things and the lofty cultural world of ideas and theories" (Adams, this issue, p. 90). The range of final miniprojects and differing student evaluations led me to conclude that, while the class was effective for some, for others the divide to which Adams alludes remained firmly in place and may even have been further reinforced through the course. The student evaluations that were submitted at the conclusion of the course - far wider and less comfortably clustered than most-are particularly revealing. In one, a clearly frustrated student remarked: "This is a course in 
glorified cataloguing - not how the time of Yale students should be used." This echoes Adams's point: perceived value lies in intellectual forays and adventures - engineering of sorts - rather than the granular mechanics of everyday operations and applications. Simply put, teaching the importance of metadata, understanding the complexity of copyright, and assessing different approaches to digitization were interpreted by some as low-hanging fruit disconnected from the more glamorous design and deployment of online tools and public-facing digital platforms.

In a similar vein, responding to a question asking for an overall assessment of the class, another student reflected: "Kind of a strange class. We didn't really learn anything but the process of digitization. While that's not nothing, it felt all very meta" and went on to conclude: "the final project was an enormous amount of work and we didn't really learn anything in the class besides what we taught ourselves. It was certainly a new kind of class though and if the digital humanities are your thing, go for it." The ambivalence felt by this student, alongside the mismatch between effort expended and the learning outcome, speaks to a widely noted tension between banal content development and exciting content delivery. While having a student acknowledge that the work is, inherently, "very meta" might be a success of some sort, such a realization does not necessarily translate into appreciation (Figure 4).

Some students strongly resisted the de-expertising that I had encouraged in the class, wanting a more classical and authoritative teacher: "The professor clearly has a wealth of knowledge on the region however he didn't teach us a thing" noted one student, quite pointedly, "the structure of the class made him more of a babysitter than a teacher." Many were frustrated by the limitations of Omeka-the software architecture that we had adopted - and wished for an easier, more intuitive interface (Figure 5). At the same time, it was clear that most of the students in the class were by no means adept digital producers. Their high consumption of digital products, interfaces, and services did not necessarily translate into a curiosity about the tools that lay behind them and the practices and techniques of digital creation.

Overall, though, most of the students did seem to appreciate the challenge and the intent through which it was delivered. "For me, it was less about actually learning about the Himalayas and more so about puzzling over the archives, trying to engage with the stories that they had to offer" wrote one, while another stated: "loved the emphasis on digital humanities and thinking critically about archival work, and the fact that we were able to make a real contribution to the archival work happening at Yale." The concluding comments in two

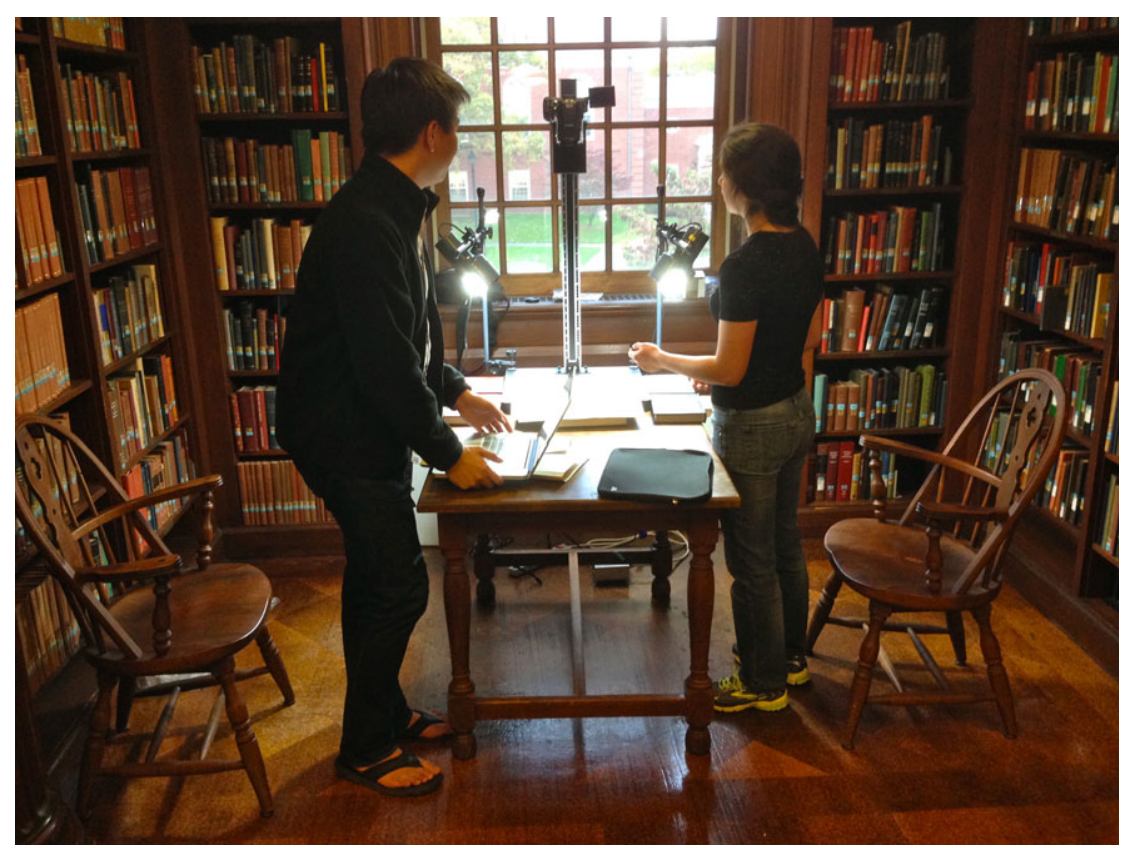

Figure 4. Students digitizing correspondence from the Himalayan Mission Archive Collection at the Yale Divinity School, 2013. 


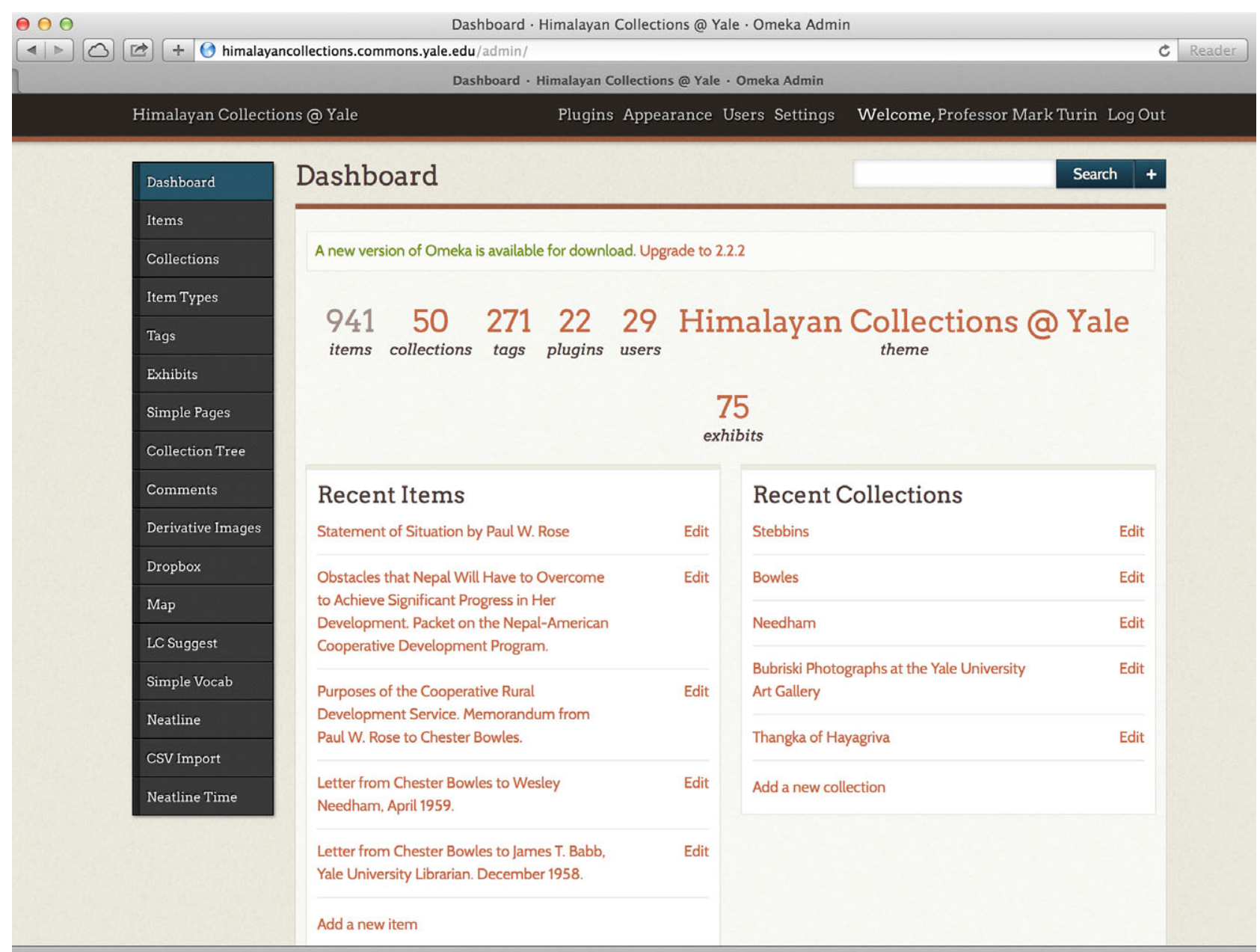

Figure 5. A screenshot of the Omeka dashboard for the class showing the number of items, collections, and users

evaluations were particularly satisfying for the four-person core instructional team, for obvious reasons:

Examining different materials every week and engaging with collections in various ways led to a completely different perspective on how courses could (and should) be taught.

There should be more classes like this or more events that encourage students to delve into the university's holdings. What good are the collections if they are not used?

\section{ACKNOWLEDGMENTS}

I am grateful to the three anonymous peer reviewers, each of whom offered targeted and welcome criticism that was constructive and challenging in generative ways, and to Kathleen Adams for her editorial guidance and intellectual leadership. I am very thankful to Sarah Calhoun, Trip Kirkpatrick, and Luke Wagner-the core instructional team of "Himalayan Collections"- for their creativity in the class and for their openness to the experimentation that it involved. We were well supported by the entire Yale Library system, and I thank university librarian Susan Gibbons in particular for her leadership and commitment to seeing Yale's collections become sites of conversation and connection. The class was enriched by the resources provided by the Yvonne and Jack McCredie Fellowship in Instructional Technology that facilitated the inclusion of a graduate teaching fellow and covered the costs of many of our guest lecturers.

\section{NOTES}

1. Named after Gordon E. Moore, co-founder of the Intel Corporation, "Moore's law" is the observation that, over the history of computing hardware, the number of transistors in an integrated circuit (and thus the power of computing) doubles every two years.

2. Online at http://www.digitalhimalaya.org, accessed April 30, 2015 . 
3. Online at http://himalayancollections.commons.yale.edu, accessed April 30, 2015.

\section{References Cited}

Berger, John

1973 Ways of Seeing. London: BBC \& Penguin Books.

Edwards, Elizabeth, Chris Gosden, and Ruth B. Phillips, eds.

2006 Sensible Objects: Colonialism, Museums, and Material Culture. Oxford: Berg.

Gosden, Chris, and Yvonne Marshall

1999 The Cultural Biography of Objects. World Archaeology 31(2):169-178.

Hallam, Jessica

2013 Himalayan Exhibit Unites Regional Artifacts. Yale Daily News, February 6: 4.

Hirsch, Brett D., ed.

2012 Digital Humanities Pedagogy: Practices, Principles and Politics. Cambridge: Open Book Publishers.

Horst, Heather A., and Daniel Miller, eds.

2012 Digital Anthropology. London: Bloomsbury Publishing.
King, Alison

1993 From Sage on the Stage to Guide on the Side. College Teaching 41(1):30-35.

Mayhew, Nicholas

2006 Cultural Property: A Contribution to the Debate. In Who Owns Objects?: The Ethics and Politics of Collecting Cultural Artefacts. Eleanor Robson, Luke Treadwell, and Christopher Gosden, eds. Pp. 83-90. Oxford: Oxbow Books.

Monaco, James

1981 How to Read a Film: The Art, Technology, Language, History, and Theory of Film and Media. New York: Oxford University Press.

Scott, Mary Katherine

2012 Engaging with Pasts in the Present: Curators, Communities, and Exhibition Practice. Museum Anthropology 35(1):1-9.

Turin, Mark

2012 Salvaging the Records of Salvage Ethnography: The Story of the Digital Himalaya Project. Book $2.01(1): 39-46$. 